\section{International Journal of

DOI: 10.31695/IJASRE.2019.33197
E-ISSN : 2454-8006

Volume 5, Issue 5

May - 2019

\title{
Experimental Assessment of Diesel Fuel Injection System Faults Using Vibration Signal Analysis
}

\author{
Prof. Dr. Sabry Allam ${ }^{1}$, Mohammed Abdo ${ }^{1}$ and Dr. M. Rabie ${ }^{2}$ \\ 1. Automotive Technology Department, Faculty of Industrial Education, Helwan University, Cairo, \\ Egypt. \\ 2. Automotive Engineering Department, Faculty of Engineering, Minia University, Minia, Egypt. \\ Corresponding author: allam@techedu.helwan.edu.eg
}

\begin{abstract}
Different tries have been presented to detect the faults of diesel fuel injection systems using vibration signal analysis and to ensure that this strategy is effective in detecting errors. In this paper, an attempt to detect the diesel injection system faults by analyzing its vibration signals using the angular range is presented. The time -frequency band was used to detect a series of faults such as; injections pressure, injected fuel quantity, and injection timing. This technique is useful because it does not need to decode and test the parts in a traditional way to detect faults. Throughout this paper, it has proved the possibility to use these techniques to detect these faults simply.
\end{abstract}

Key words: Diesel injection system, Vibration; faults, Aangular range,Iinjection pressure,Iinjection timing, Ttime -frequency band.

\section{INTRODUCTION}

The protection of internal combustion engines and their effectiveness raises major industry concerns. Condition monitoring help engines maintain optimum efficiency and performance, but it is often difficult for the maintenance team to troubleshoot engine faults. Traditional preventive maintenance not only wastes the machine time but also replaces the early parts. The successful implementation of the condition monitoring program allows the device to operate at full capacity without having to stop the machine at specified intervals [1, 2]. Vibration analysis is a method used to monitor the state of the engine. Vibration extraction techniques have an important role in diagnosing internal combustion engines. Several techniques have been proposed to extract the vibration signal during some past years.

Z. Ranachowski and A. Bejger [2] diagnosed the common faults of the fuel injection system for the marine diesel engine using a portable system to record the vibration signal. Liu Jianmin et al. [3] diagnosed a defect in the diesel injection system by monitoring the vibration signal from the head of the engine cylinders. Analysis of this signal showed that the injection information could be described and used in diagnosing the faults of the fuel injection system.

Suphattharachai and Chomphan [4] introduced a new strategy in engine fault detection as a tool for engine maintenance technicians. This was done using vibration analysis of the engine in normal and abnormal condition. Three different faults were applied to the engine to achieve a satisfactory result in the use of this technique in detecting engine faults.

Ben-Ari et al. [5] have demonstrated the possibility of using a vibration signature to determine the source of the fault. By performing a series of experiments to monitor the vibration of the engine block in normal and abnormal conditions and found that the vibration level of the engine provides important information to diagnose the condition of the engine. The fault in the oil pump was determined by analyzing the recorded vibration signal for several consecutive tests of the faulty engine and the fault-free engine under the idling condition [6].

E. Ftoutou et al. [7] were able to detect a fault in the diesel engine when the vibration signal was measured respectively in 7 positions on the engine block and cylinder head by piezoelectric accelerometer. By blocking of injector hole is supposed to be the cause of misfire of cylinder 1 found that at idle speed, this fault can only be detected through by the peak to peak value (PP), root mean square value (RMS) features and an accelerometer positioned near the misfired cylinder or in the middle of the engine block. Through signal processing and theoretical analysis of recorded vibration signals of high pressure fuel injection pipe nozzles 


\section{International Journal of Advances in Scientific Research and Engineering (ijasre), Vol 5 (5), May-2019}

from different cylinders with different advance angles for fuel injection, an important parameter the fuel injection advance angle was extracted, which was used to identify the state of fuel injection and described the relationship between the fuel injection advance angles and the vibration characteristic quantities of high-pressure fuel injection pipes' nozzle [8]. The engine vibration sources were checked when the exhaust valve clearance was changed from a "healthy" to a "faulty".By applying the time domain and the frequency domain methods to extract useful information and determine the condition of the diesel engine under different loads and speeds we found that signatures of vibration engine body are rich in information about operating parameters and physical condition [9]. It is recommended to use the 'Wigner Trispectrum (WT)' method to describe the properties of the vibration signals obtained from the diesel engine because the analysis of the diesel engine vibration signal is both nonlinear and nonstationary [10]. The results of fault detection from valve deformation and change of valve clearance in a diesel engine indicate the accuracy of the application and the possibility of using the engine vibration analysis system [11].

Shulin and Duan [12] proposed a novel method combining local wave decomposition (LWD) and lifting wavelet denoising to use for feature extraction and condition evaluation of diesel engine vibration signals. The vibration signals of diesel engine pistonliner wear are analyzed, and the results showed that the method is feasible and effective in feature extraction and condition evaluation of diesel engine faults. Chao Jin et al [13]presented technique of diagnosing combustion faults and valve leakage by combining vibration signal with cylinder pressure and revolution speed signals. they used the wavelet decomposition method to extract features from data collected under different health conditions.

Alireza Zabihi-Hesari et al [14] also implemented a technique capable of distinguishing between the normal and faulty operation of a diesel engine using fast Fourier transform, discrete wavelet transforms and artificial neural network. Shiyuan Liu et al [15] designed a simple diagnostic technique called partial sampling and feature averaging (PSFA). The experimental results showed that the proposed technique was feasible, efficient and simple to implement.

\section{EXPERIMENTAL SYSTEM}

The test stand that was used through experimental work of this research and its contracture drawing are shown in Figure 1 and 2. The diesel fuel injection system was coupled to a test bench which allows maintaining a constant speed and simulation of the system with several faults during the tests. The diesel fuel injection system has inline injection pump (Kiki type) was used in the experimental which has Injection sequence (1-2-4-3). Test bench Hartridge 600 series type is device to test a high-pressure diesel fuel injection system. Pressure was acquired using a BD 26.600 sensor. A PCB 333B32 sensor with a frequency range of $0.5 \mathrm{~Hz}-$ $3 \mathrm{kHz}$ was used to measure vibration signal. Crank angle measured by proximity sensor which give one pulse per revolution. LMS pimento instrument system was used for data acquisition and signal processing.

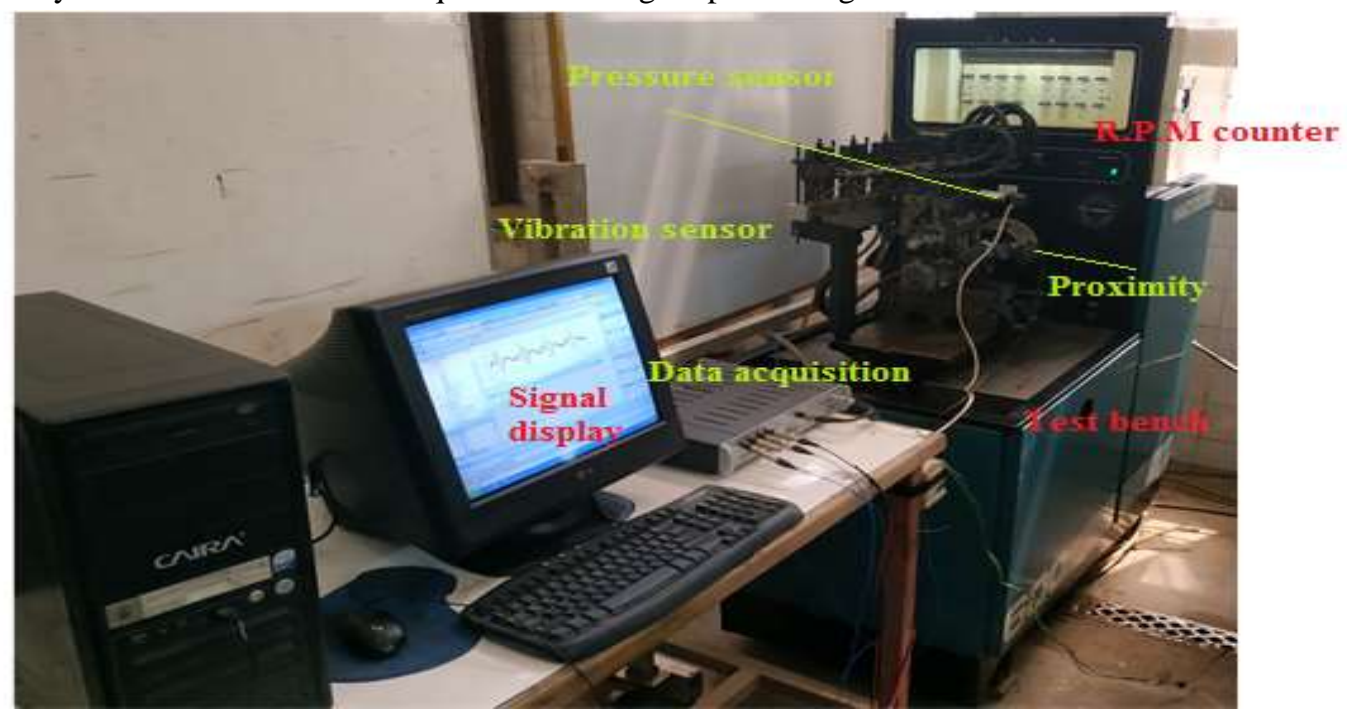

Figure 1. Main components of the test rig 


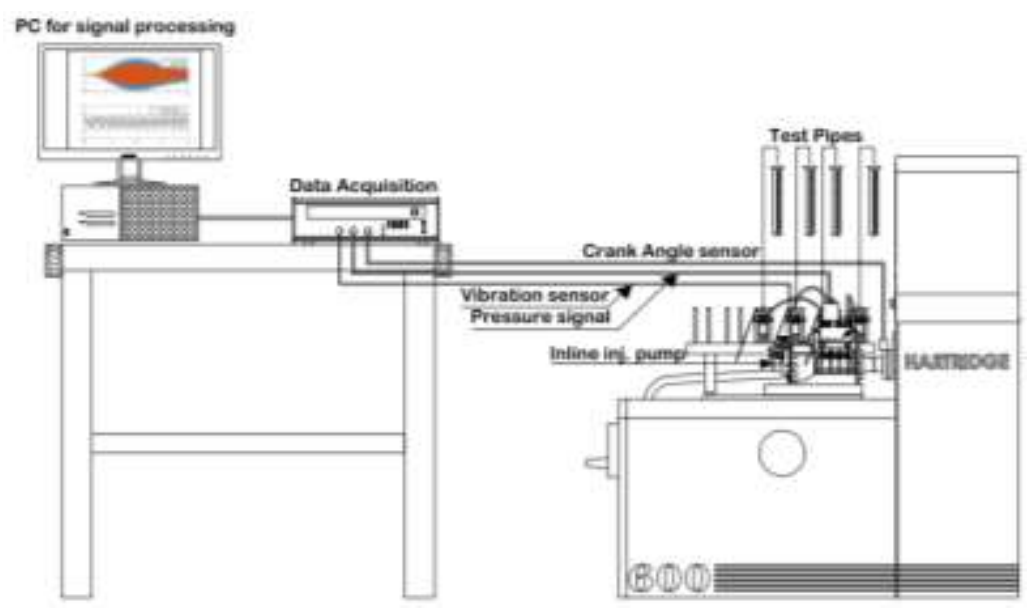

Figure 2. Main components of the test rig (block diagram).

\section{MEASUREMENT PROCEDURES:}

The measurement procedures are presented as followed

1. The vibration sensor mounted on the injector's carrier.

2. Normal injection pressure is $120 \mathrm{bar}$, injected fuel quantity $3 \mathrm{~cm}^{3}$ every 100 inject, standard injection timing for every unit at constant speed pump shaft of $500 \mathrm{rpm}$.

3. Perform injection fault (zero injection pressure) at each injector at the same speed of $500 \mathrm{rpm}$.

4. Implementation of the supply failure and reduce the amount of fuel injected per unit when the speed of speed of $500 \mathrm{rpm}$.

5. Decreasing injected fuel quantity for every injection unit at constant speed pump shaft of $500 \mathrm{rpm}$ from $3 \mathrm{~cm}^{3}$ to $1 \mathrm{~cm}^{3}$ every 100 inject.

6. Increasing injected fuel quantity for every injection unit at constant speed pump shaft of $500 \mathrm{rpm}$ from $3 \mathrm{~cm}^{3}$ to $5 \mathrm{~cm}^{3}$ every 100 inject.

7. Early injection timing for every injector 25 degree before the normal injection timing at constant speed pump shaft of 500 rpm.

8. Late injection timing for injector No. 425 degree after the normal injection timing at constant speed pump shaft of 500 rpm.

\section{RESULTS}

In the angular domain, the analysis can clearly correlate vibration events to the operation of DFIS. The injection events for each cylinder occur at crank angles of around $180^{\circ}, 360^{\circ}, 540^{\circ}$ and $720^{\circ}$, consistent with the firing order of 1-2-4-3.

\subsection{Injection Pressure Fault Detection}

Figure 3 shows the vibration signal when the injection pressure of injector No. 1 was reduced to zero while, the reference vibration signal corresponding to the normally condition is shown in figure 3 in blue color in order to compare with the faulty vibration signal presented in red color.

The transient vibration signals occurring four times per cycle, which are essentially caused by the injection units and the injectors. When injection pressure was reduced to zero bar for injector one, fuel wasn't injected. Hence the vibration signal transient related to injector No.1, shown in figure 3 became weaker than that of the healthy condition as shown in Figure 3. 


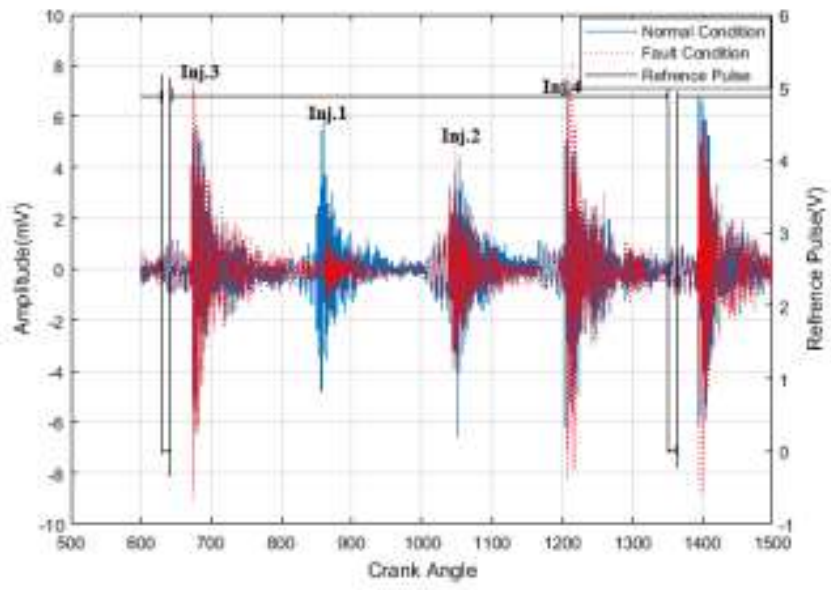

Figure 3. Vibration signal in angular-domain from DFIS running at speed of $500 \mathrm{rpm}$ with fault in injector No. 1 (zero injection pressure).

Frequency-domain analysis gives spectral information of vibration signals by transforming them from the angular-domain to the frequency-domain. The common, obvious characteristics in the spectrum of vibration signals are the injection frequency and its harmonics. Figure 4 shows the amplitude of vibration response against frequency.

The vibration signals in the frequency domain are obtained using the Fast Fourier Transformation (FFT). Figure 4 shows the spectrum of the healthy condition in blue as well as the spectrum of the faulty condition red. It can be seen from Figure 4 that high vibration energy can be observed between 0 and $7 \mathrm{KHz}$. But on clear change could be observed in the spectra even when the injection pressure was reduced. It isn't possible to determine which cylinder has a faulty injector from the spectrum because The Fourier transform does not take time information into account, it simply identifies all frequencies contained in the signal.

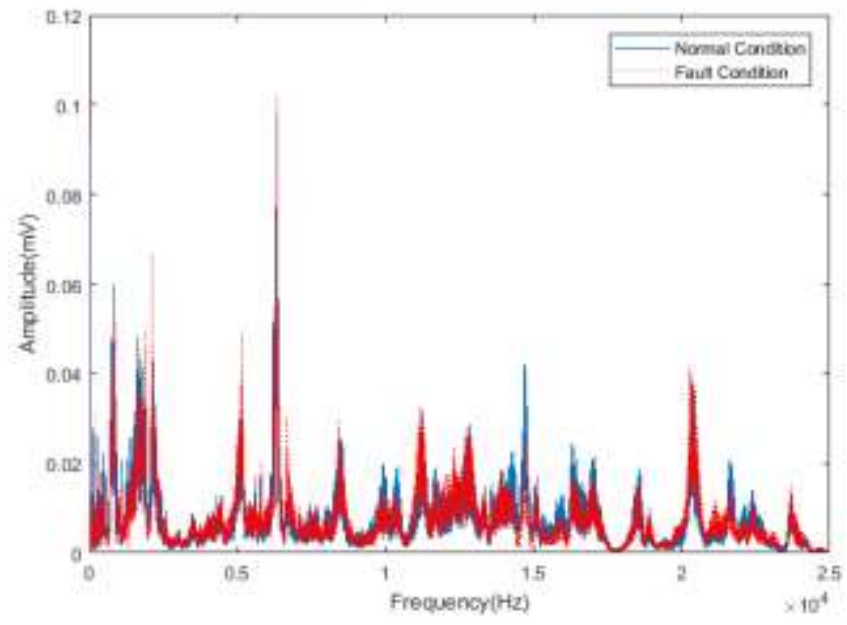

Figure 4. Frequency spectrum of vibration signal from DFIS at $500 \mathrm{rpm}$ with fault in injector No. 1 (no injection pressure).

Time-frequency domain analysis is a signal processing technique that makes it possible to see both the time and frequency information at the same time. It displays the combined results from time and frequency analysis in a three-dimensional way which plots the amplitudes against time and frequency axes as shown in Figures 5 and 6.

Figures 5 and 6 show the result of time-frequency domain analysis of the vibration signal given in Figure 3. Large vibration events occur at specific time, every $50 \mathrm{~ms}$, when the fuel was injected of each injector. 


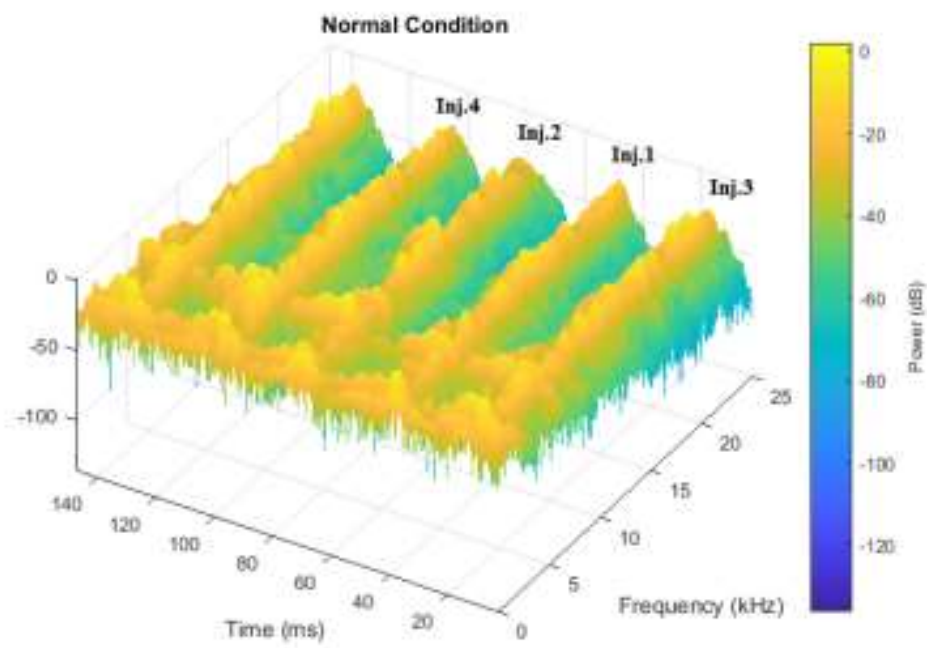

Figure 5. Time-frequency domain of vibration signal from DFIS at $500 \mathrm{rpm}$ in normal condition.

Weak signal components in the frequency range from $0 \mathrm{kHz}$ to $10 \mathrm{kHz}$ could be clearly observed from Figure 6 when the injection pressure was reduced to zero bar for injector No. 1.

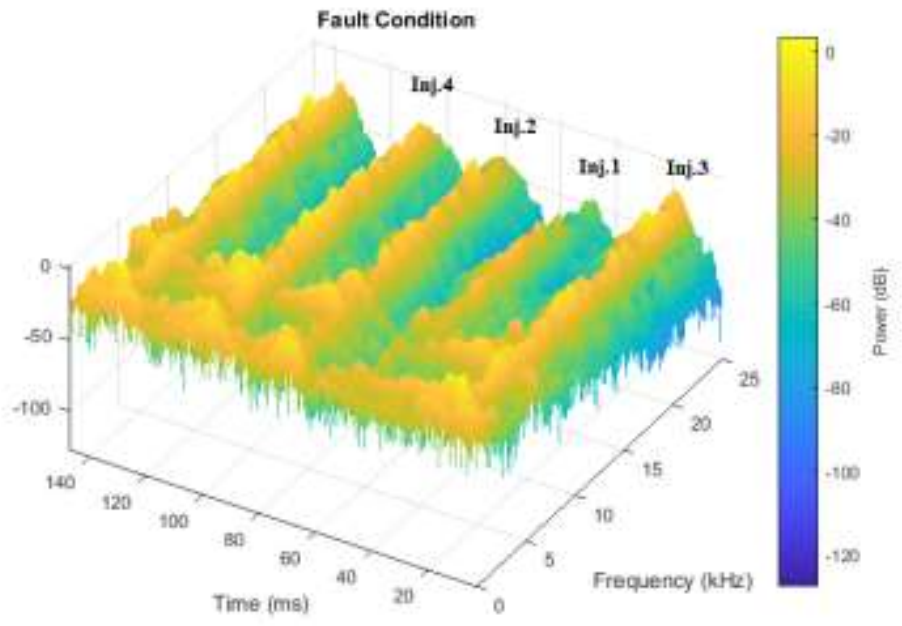

Figure 6. Time-frequency domain of vibration signal from DFIS at $500 \mathrm{rpm}$ with fault in injector No. 1 (no injection pressure).

By applying the same fault (no injection pressure) on the remaining injectors, the fault can be seen clearly in figures 7,8 and 9 .

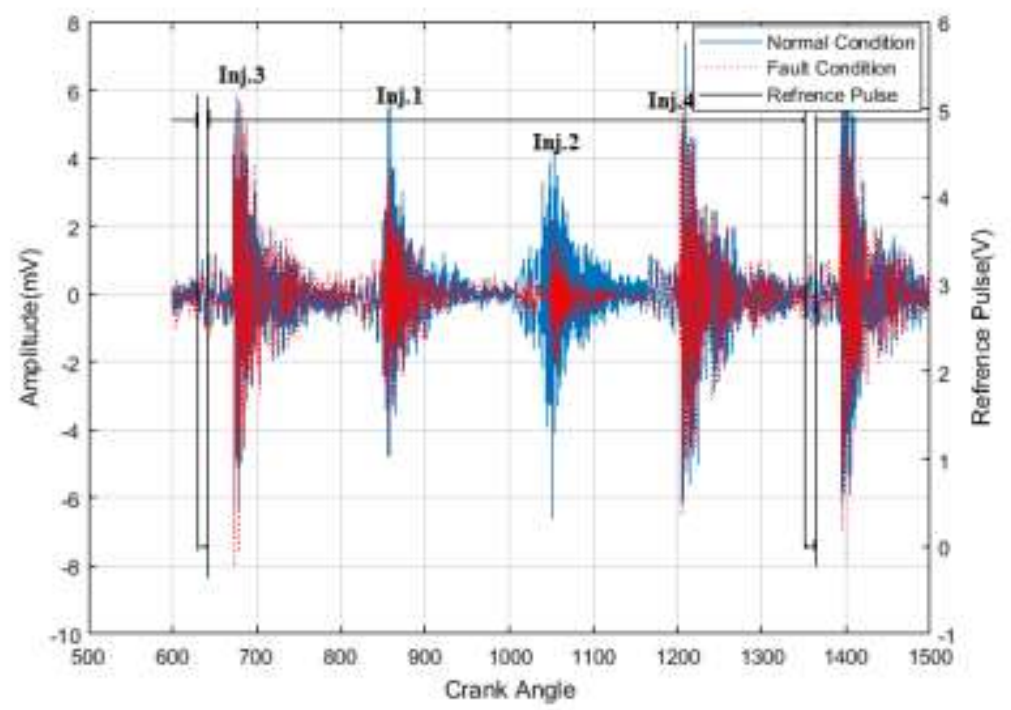

Figure 7. Vibration signal in angular-domain from DFIS running at speed of 500 rpm with fault in injector No. 2 (zero injection pressure). 


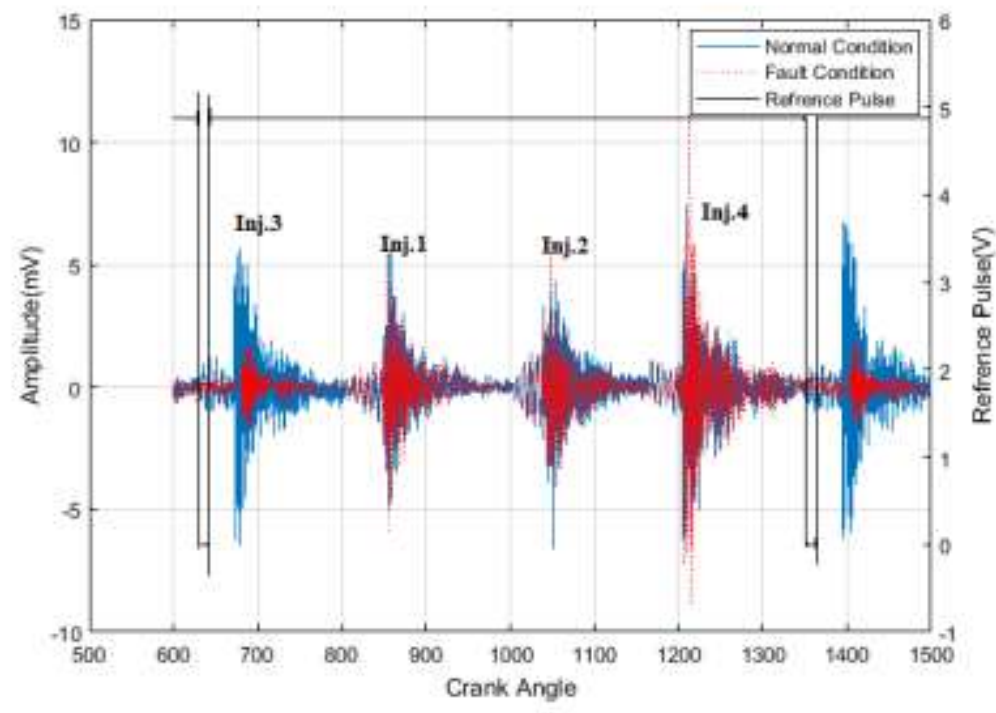

Figure 8. Vibration signal in angular-domain from DFIS running at speed of $500 \mathrm{rpm}$ with fault in injector No. 3 (zero injection pressure).

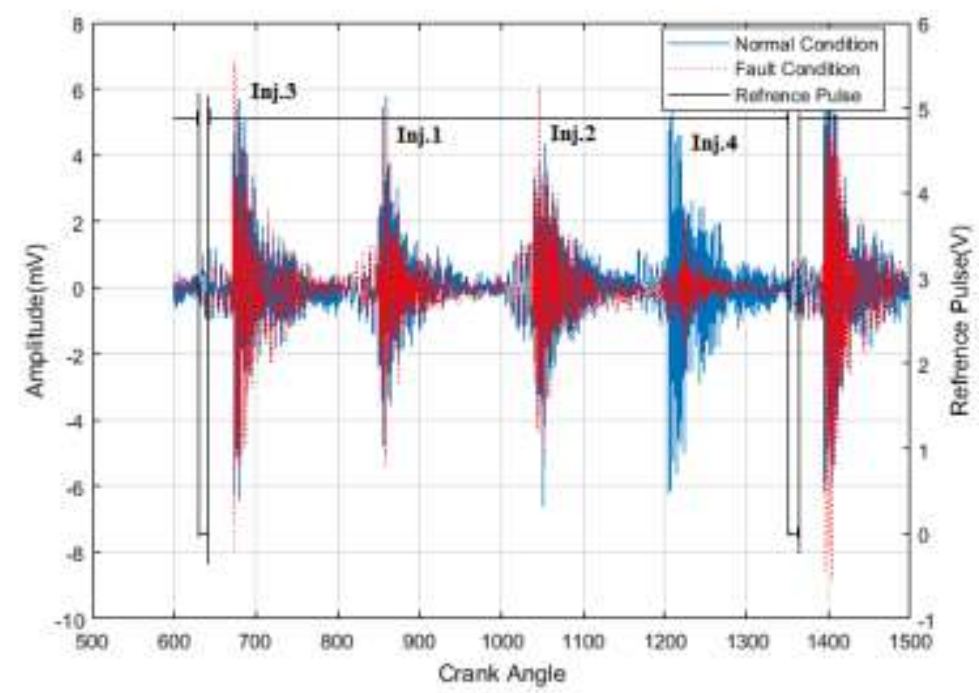

Figure 9. Vibration signal in angular-domain from DFIS running at speed of $500 \mathrm{rpm}$ with fault in injector No. 4 (zero injection pressure).

\subsection{Fuel Quantity Fault Detection}

\subsubsection{Fuel quantity reduction}

Figure 10 shows the vibration signal when the injected fuel quantity of injector No. 1 was reduced to $1 \mathrm{~cm}^{3}$ instead of $3 \mathrm{~cm}^{3}$. The injected fuel quantity fault is clear in figure 10. The fault is a reduction in the fuel injection period while the start of injection timing in both signals is equal, but the injection terminated in the faulty signal early. 


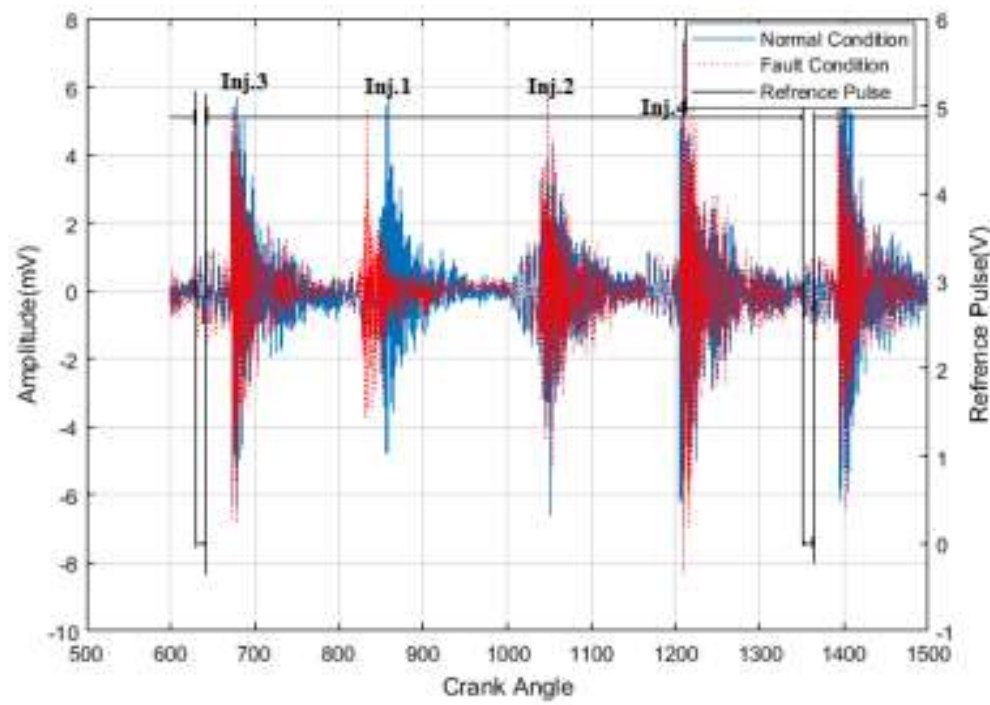

Figure 10. Vibration signal in angular-domain from DFIS running at speed of 500 rpm with fault in injector No. 1 (reducing injected fuel quantity).

The difference between the two signals can be illustrated in the frequency domain as shown in figure 11 . Using the timefrequency domain, the signals of the injection events can be displayed separately, in order to easily detect the fault and locate it as shown in figure 12 .

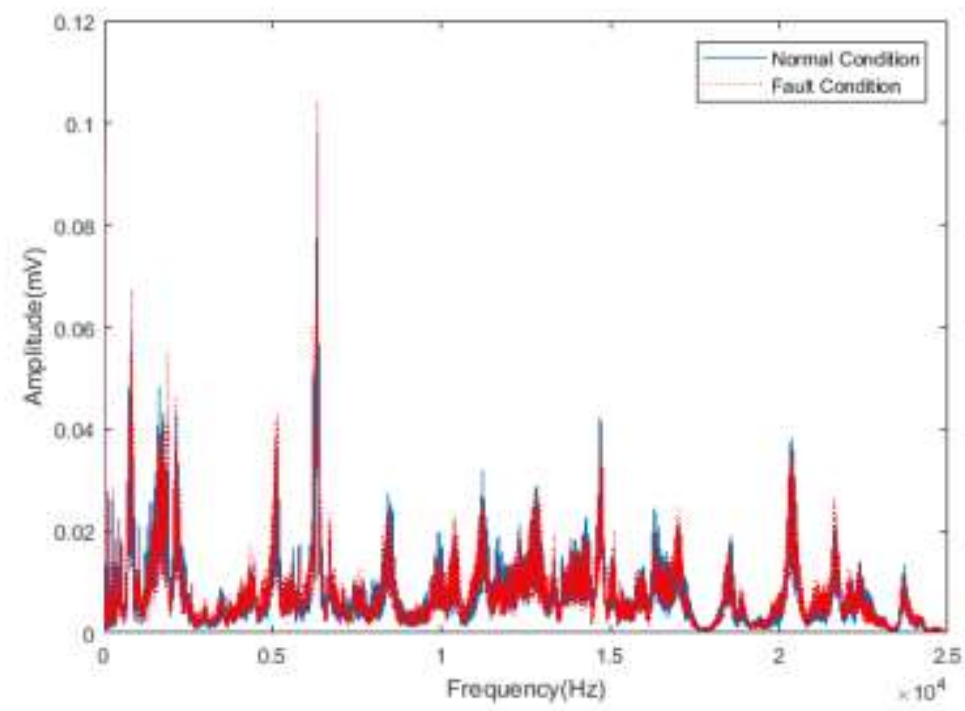

Figure 11. Frequency spectrum of vibration signal from DFIS at $500 \mathrm{rpm}$ with fault in injector No. 1 (reducing injected fuel quantity).

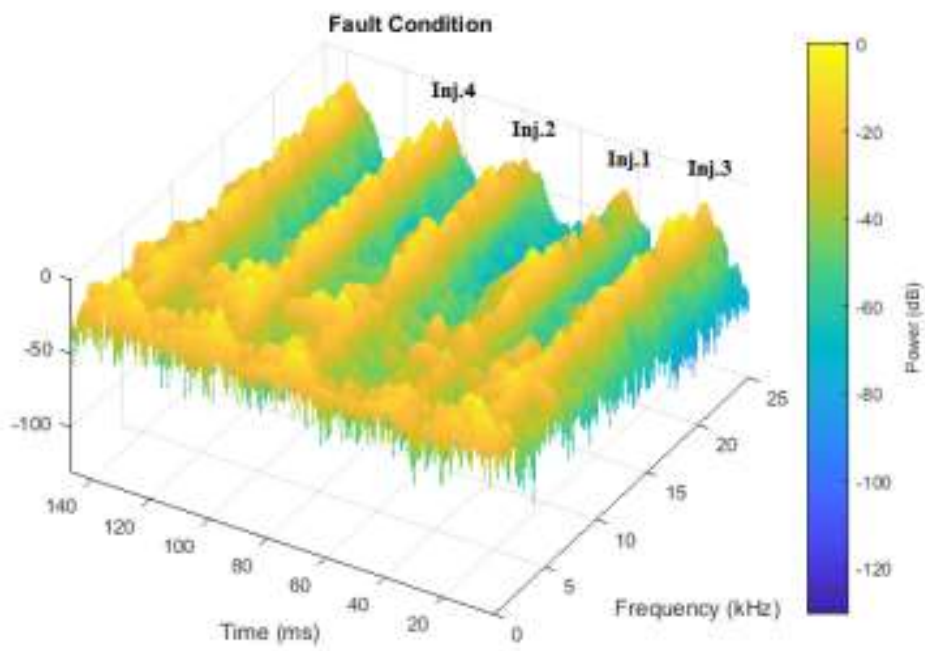

Figure 12. Time-frequency domain of vibration signal from DFIS at $500 \mathrm{rpm}$ with fault in injector No. 1 (reducing injected fuel quantity). 


\subsubsection{Fuel quantity increasing}

Figure 13 shows the vibration signal when the injected fuel quantity of injector No. 1 was increased from $1 \mathrm{~cm}^{3}$ to $5 \mathrm{~cm}^{3}$.

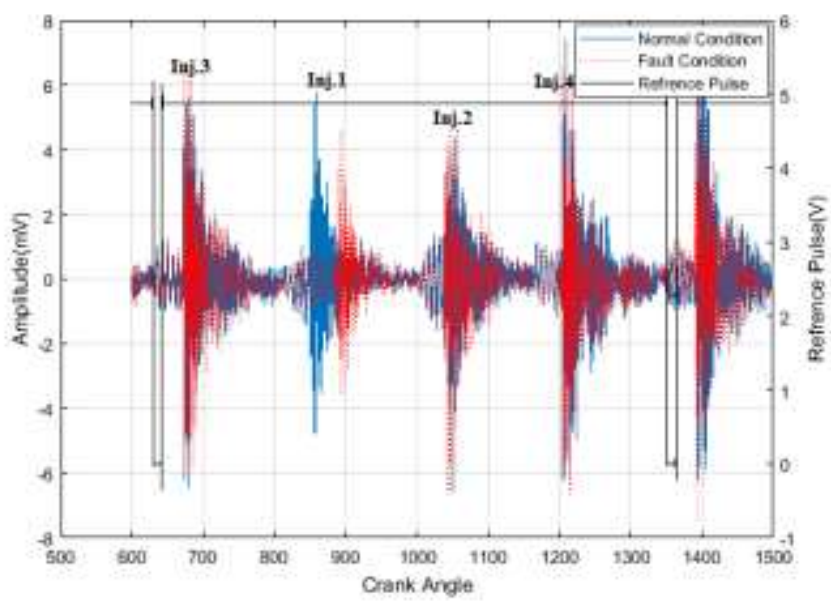

Figure 13. Vibration signal in angular-domain from DFIS running at speed of $500 \mathrm{rpm}$ with fault in inject No. 1 (increasing injected fuel quantity).

The fault due to the increasing of injected fuel quantity at the injector No. 1 is clear in figure 13. The fault is an increase in the fuel injection period and the start of injection timing in both signals is equal, but the injection terminated in the faulty signal late as shown in figure 13. Also, the difference between the two signals can be illustrated in the frequency domain as shown in figure 14. Using the time-frequency domain, the signals of the injection events can be displayed separately, in order to easily detect the fault and locate it as shown in figure 15.

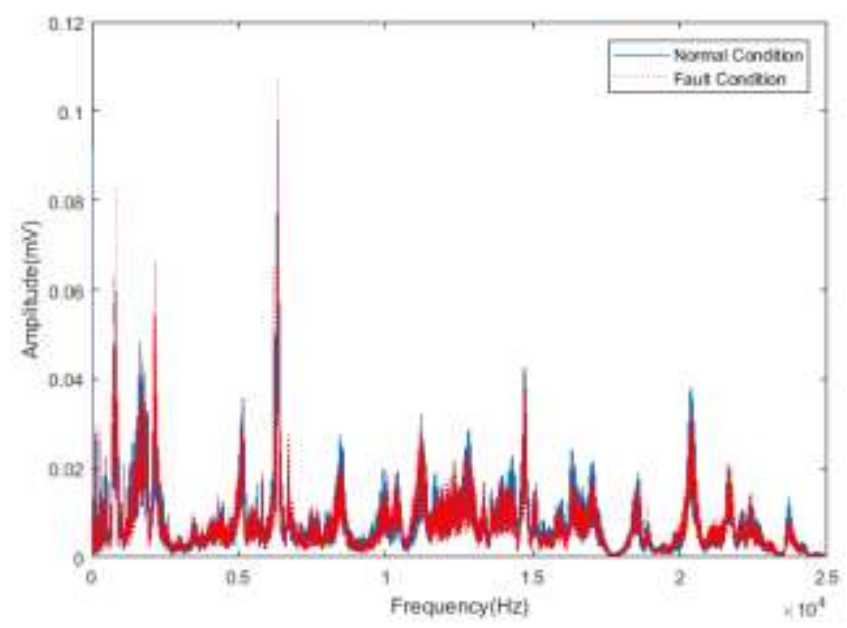

Figure 14. Frequency spectrum of vibration signal from DFIS at $500 \mathrm{rpm}$ with fault in injector No. 1 (increasing injected fuel quantity).

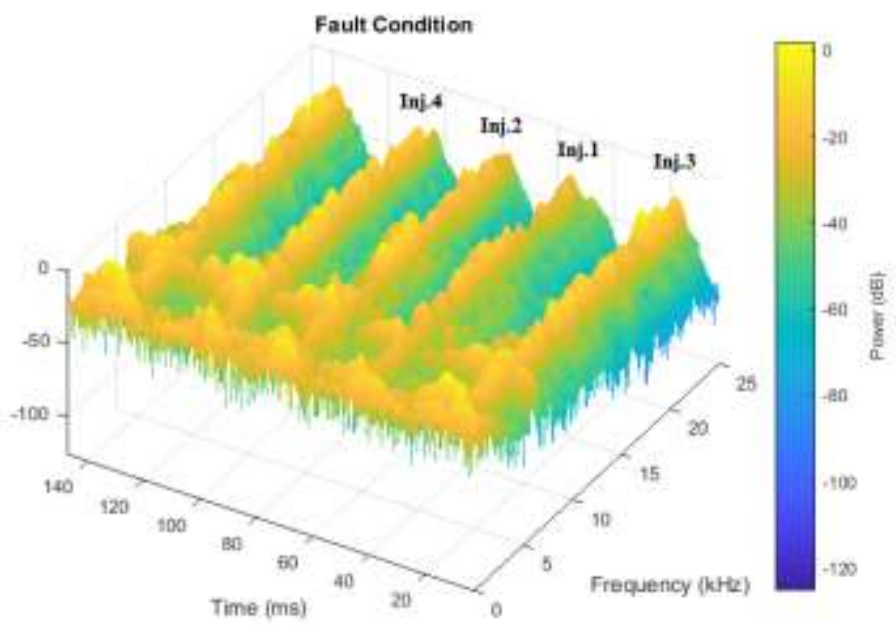

Figure 15. Time-frequency domain of vibration signal from DFIS at $500 \mathrm{rpm}$ with fault in injector No. 1 (increasing injected fuel quantity). 
International Journal of Advances in Scientific Research and Engineering (ijasre), Vol 5 (5), May-2019

\subsection{Fuel Injection Timing Fault Detection}

4.3.1. Advanced injection timing

Figure 16 shows the vibration signal when the injection timing of injector No. 1 was advanced 25 degree before the normal injection timing.

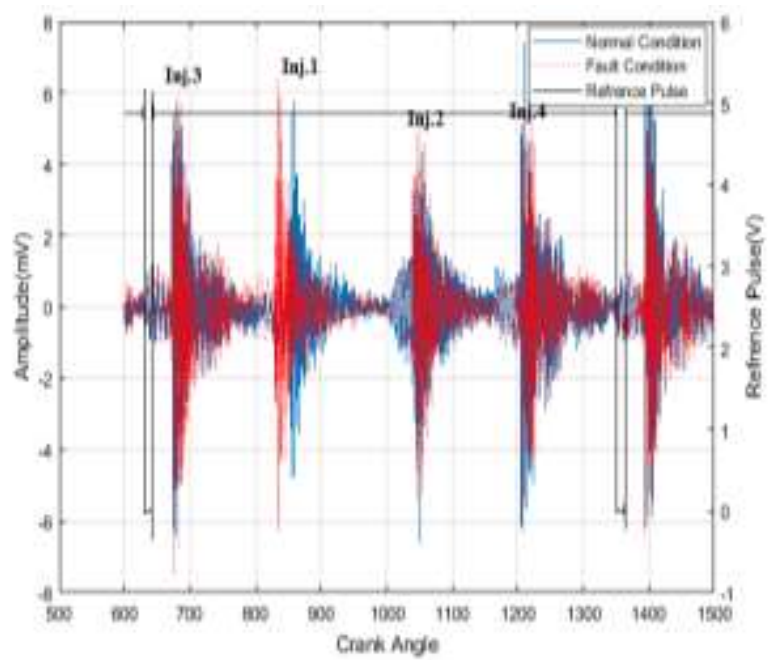

Figure 16. Vibration signal in angular-domain from DFIS running at speed of 500 rpm with fault in injector No. 1 (early injection timing).

The injection timing fault is clear as shown in figure 16 at the injector event No. 1 . The fault is the injection of fuel early and the injection period in the faulty signal is as equal as in the healthy signal as shown in figure 16. The difference between the two signals can be illustrated in the frequency domain as shown in figure 17. And through time-frequency domain, the signals of the injection events can be displayed separately, in order to easily detect the fault and locate it as shown in figure 18.

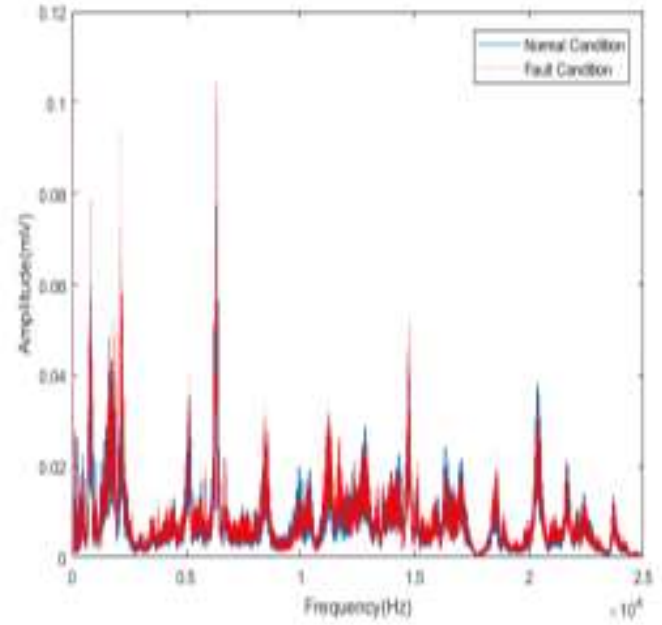

Figure 17. Frequency spectrum of vibration signal from DFIS at $500 \mathrm{rpm}$ with fault in injector No. 1 (early injection timing).

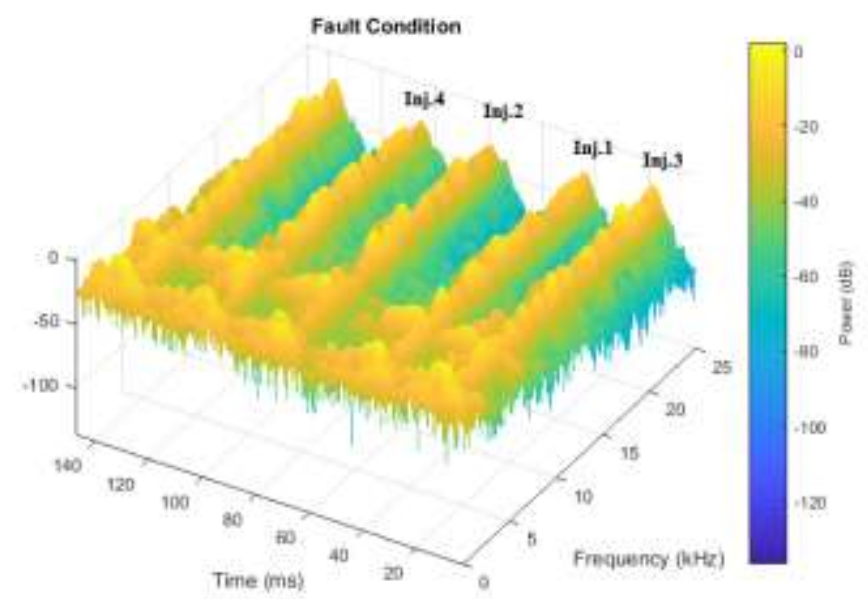

Figure 18. Time-frequency domain of vibration signal from DFIS at $500 \mathrm{rpm}$ with fault in injector No. 1 (early injection timing). 


\subsubsection{Retarded injection timing}

Figure 19 shows the vibration signal when the injection timing of injector No. 1 was retarded 25 degree after the normal injection timing.

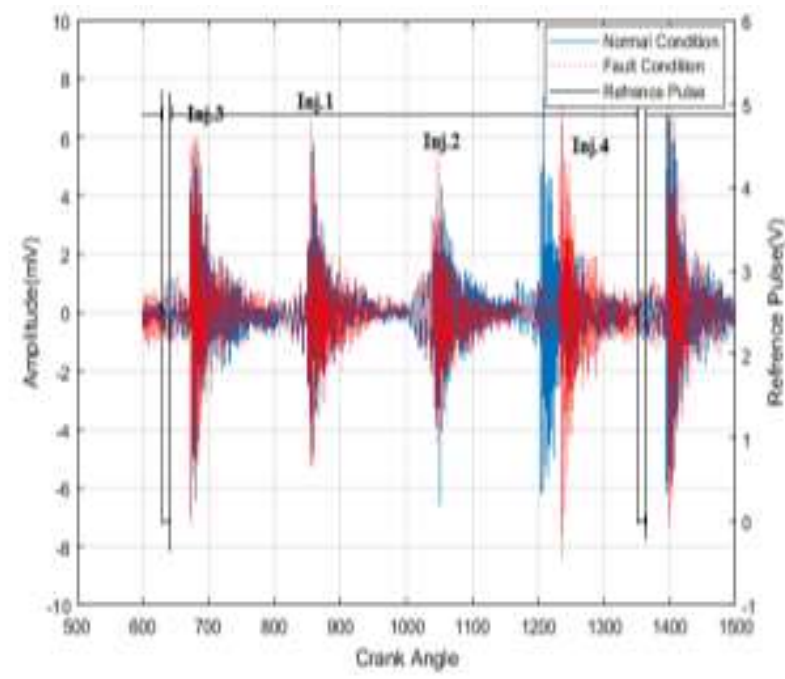

Figure 19. Vibration signal in angular-domain from DFIS running at speed of $500 \mathrm{rpm}$ with fault in injector No. 4 (late injection timing).

The late injection timing fault of injector No. 4 can be seen in Figure 19. The difference between the two signals can be illustrated in the frequency domain as shown in Figure 20.

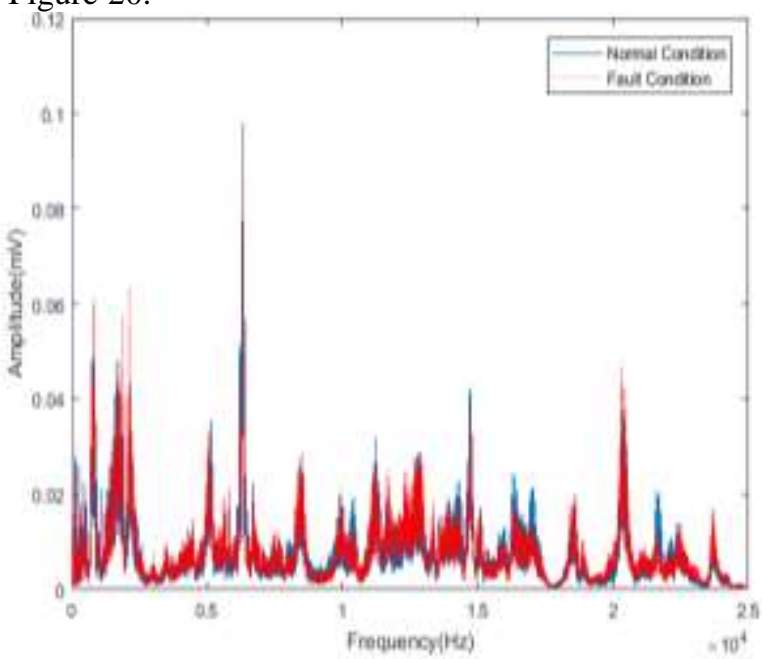

Figure 20. Frequency spectrum of vibration signal from DFIS at $500 \mathrm{rpm}$ with fault in injector No. 4 (late injection timing).

Using the time-frequency domain technique, the signals of the injection events can be displayed separately, in order to easily detect the fault and locate it as shown in figure 21 .

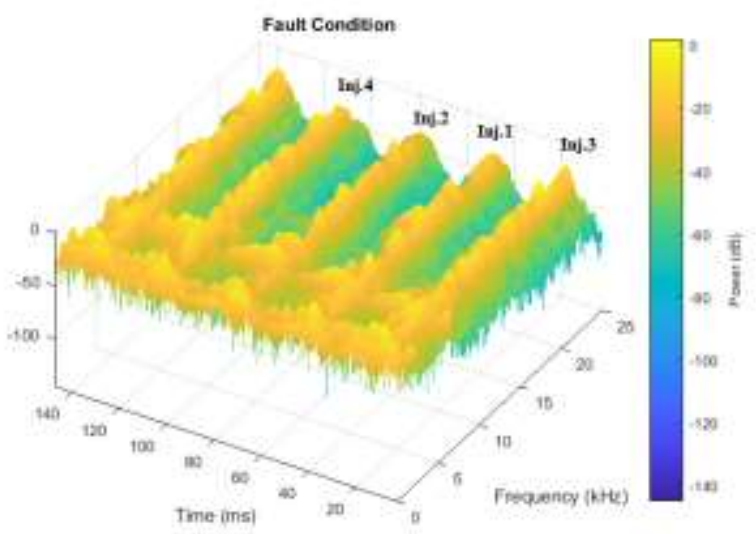

Figure 21. Time-frequency domain of vibration signal from DFIS at $500 \mathrm{rpm}$ with fault in injector No. 4 (late injection timing). 
International Journal of Advances in Scientific Research and Engineering (ijasre), Vol 5 (5), May-2019

\section{SUMMARY}

This research presents the possibility of using vibration analysis in detecting three faults of diesel fuel injection system. Three conditions of system faults including the injection pressure, the injection timing, and the injected fuel quantity are examined. The reference vibration signal and the faults vibration signals were obtained. Based on different signal processing in MATLAB program, the results of the measured results were presented in three domains, angular domain, frequency domain, time -frequency domain. The frequency domain is not a suitable technique for non-stationary signals, and transient signals which are important in diesel fuel injection system normally highly non-stationary. It was necessary to use the most common of the current method for obtaining the time-frequency distribution is the short-time Fourier transform (STFT) which maps a signal onto the time-frequency domain and it is sensitive to transient signals. Also, the angular domain proved an easy way to detect the three applied faults experimentally.

\section{REFERENCES}

[1] C. D.1., "A new method of processing rolling element bearing signals," in proceeding 20th annual meeting of the vibration institute, 1996.

[2] Z. Ranachowski,a. Bejger, "Fault diagnostics of the fuel injection system of a medium power maritime diesel engine with application of acoustic signal," Archives of acoustics, vol. 30, p. 465-472, 2005.

[3] Liu Jianmina, Shi Yupenga, Zhang Xiaominga, Xu Shiyongb,Dong Lijunc, "Fuel Injection System Fault Diagnosis Based on Cylinder Head Vibration Signal," Procedia Engineering , vol. 16, pp. 218-223, 2011.

[4] S. Chomphan, "Vibration analysis of gasoline engine faults," American journal of applied sciences, vol. 10, pp. 1166-1171, 2013.

[5] Benari,J., debotton, G., Itzhaki, R., and Sher, E., "Fault Detection in Internal Combustion Engines by the Vibrations Analysis Method," SAE Transactions- Journal of Engines, vol. 108, 1999.

[6] F. Xia, "Fault diagnosis of diesel engine oil pump based on vibration signal processing," Atlantis press, vol. 123, pp. 1778$1783,2017$.

[7] E. Ftoutou, m. Chouchane, n. Besbès, r. Ouali, "Detection of diesel engine misfire by vibration analysis," In congrès Tunisien de mécanique cotum'08, hammamet, 2008.

[8] Z. Wang, "Study on fault diagnosis of fuel injection based on vibration signal analysis of high-pressure fuel injection pipe," Applied physics research ccse, vol. 1, pp. 102-106, 2009.

[9] Yousef Alhouli, Abdullah Alkhaledi, Abdulaziz Alzayedi, Mohsen Alardhi \& Ahmed I. Abed, "Study of Diesel Engine Vibration Condition Monitoring," Global Journal of Researches in Engineering, vol. XV, pp. 37-44, 2015.

[10] S. Xiaochun and h. Hongying, "diesel engine fault diagnosis and classification," in 8th international conference on signal processing, beijing, 2006.

[11] Flett, J. Bone and G. M., "Fault detection and diagnosis of diesel engine valve trains," Mechanical Systems and Signal Processing, vol. 72-73, pp. 316-327, May 2016.

[12] Wang F., Duan S, "Fault Diagnosis of Diesel Engine Using Vibration Signals," in Intelligent Computing and Information Science, Berlin, 2011.

[13] Chao Jin ; Wenyu Zhao ; Zongchang Liu ; Jay Lee ; Xiao He, "A vibration-based approach for diesel engine fault diagnosis," in International Conference on Prognostics and Health Management, Cheney, WA, USA, 2014.

[14] Alireza Zabihi-Hesari,Saeed Ansari-Rad, Farzad A Shirazi and Moosa Ayati, "Fault detection and diagnosis of a 12-cylinder trainset diesel engine based on vibration signature analysis and neural network," Mechanical Engineering Science, p. 1-14, June 3, 2018.

[15] Shiyuan Liu, Fengshou Gu and A Ball, "Detection of engine valve faults by vibration signals measured on the cylinder head," Proceedings of the Institution of Mechanical Engineers Part D Journal of Automobile Engineering, vol. 220, pp. 379386, 2006. 